\title{
ANALISIS PERSEPSI AUDITOR MENGENAI FAKTOR PENENTU AUDIT FEE BERDASARKAN CLIENT ATTRIBUTES, AUDITOR ATTRIBUTES, DAN ENGAGEMENT ATRTRIBUTES
}

\author{
Oleh: \\ Aman Faturachman \\ (Dosen Program Studi Akuntansi FPEB Universitas Pendidikan Indonesia) \\ Tri Novi Fuji L \\ (Alumni Program Studi Akuntansi FPEB Universitas Pendidikan Indonesia)
}

\begin{abstract}
This research purposes to know how perception auditors about determining factors of audit fee based on Client Attributes, Auditor Attributes, and Engagement Attributes at The Public Accountant Firm residing in Bandung. In this research, the indicator that is used to characterize the Client Attributes are size, complexity, inherent risk, profitability, leverage and liquidity, and industry. While the indicator to characterize the Auditor Attributes are auditor's specialization, audit tenure, and location. And the indicators to characterize the Engagement Attributes are audit problems, audit report lag, busy season, and number of reports. The Method that is used in this research is a descriptive method. The population in this research is a public accountant in Bandung. Based on sampling techniques that saturated and qualified then it take about 11 offices of public accountant. SmartPLS ver $2.0 \mathrm{M} 3$ are used as a Statistical analysis. The result of this research with count the loading factor and bootstrapping method are, the first one that the perception of the auditor based on client attributes of audit fee determinants from which is very important to not important is size, complexity, profitability, inherent risk, industry, and leverage \& liquidty, the second states that perception based on auditor attributes audit fee determinants from which is very important to not important is audit tenure, location, and specialization. And the third states that the perception of auditor engagement attributes based determinants of audit fee which is very important to not important audit report lag, busy season, audit problems and number of reports.
\end{abstract}

Keywords : Audit Fee, Client Attributes, Auditor Attributes, and Engagement Attributes

\section{Pendahuluan}

Perkembangan perusahaan go public di Indonesia mengalami kemajuan yang sangat pesat. Perkembangan ini menuntut setiap perusahaan untuk terus mempertahankan eksistensinya dalam dunia bisnis. Setiap perusahaan harus selalu melakukan suatu perbaikan dalam kegiatan operasi perusahaan. Hasil operasi suatu perusahaan selama satu periode tertentu tercermin dalam laporan keuangan. 
Laporan keuangan suatu perusahaan harus dievaluasi dengan cara dilakukannya pemeriksaan (audit) terhadap laporan keuangan perusahaan, yang tujuannya adalah untuk menilai apakah laporan keuangan tersebut telah disajikan secara benar dan wajar. Disinilah peran audit dibutuhkan sebagai suatu jasa profesi yang dilakukan oleh Kantor Akuntan Publik dan dilaksanakan oleh seorang auditor.

Profesi auditor merupakan suatu profesi yang menjadi kepercayaan masyarakat. Dalam menunjang profesionalismenya, auditor melaksanakan tugas dan tanggung jawabnya tidak terlepas dari pedoman standar audit yang ditetapkan oleh Institut Akuntan Publik Indonesia (IAPI), yaitu standar umum, standar pekerjaan lapangan, dan standar pelaporan. Auditor melaksanakan tugas dan tanggung jawabnya dalam mengaudit laporan keuangan dituntut untuk memiliki kompetensi yang memadai, sehingga ia mampu melaksanakan proses audit sesuai dengan prosedur yang telah ditetapkan, yang kemudian sebagai balasan atas jasanya akan mendapatkan fee atau imbalan yang sesuai atas jasa profesional yang telah ia berikan kepada klien. Audit fee sendiri diartikan sebagai besarnya imbal jasa yang diterima oleh auditor akan pelaksanaan jasa audit.

Audit fee sendiri di Indonesia masih menjadi perbincangan yang cukup panjang sampai saat ini, mengingat belum adanya peraturan yang menetapkan standar minimal audit fee yang akan diterima oleh auditor setelah melakukan tugasnya. Seperti halnya yang disebutkan dalam jurnal Michell Suharli (2008), yang mengatakan bahwa penetapan audit fee selama ini masih dilakukan secara subjektif, yang artinya ditentukan oleh salah satu pihak atau atas dasar kekuatan tawar-menawar antara akuntan publik dan klien dalam situasi persaingan akuntan publik. Hal ini memungkinkan penetapan fee yang terlalu rendah atau terlalu tinggi atas jasa yang diberikan, bergantung kepada kekuatan tawar-menawar tersebut.

Selain masih terjadi tawar-menawar harga, besarnya audit fee di Indonesia juga tidak tercantum secara transparan atau terperinci di dalam catatan atas laporan keuangan perusahaan. Audit fee masuk kedalam pos beban umum dan administrasi dan ditulis dengan nama akun jasa professional. Terbukti dengan data yang penulis peroleh dari laporan keuangan 432 perusahaan yang terdaftar di Bursa Efek Indonesia (BEI) hanya beberapa perusahaan yang mencantumkan biaya audit secara terpisah dari akun jasa profesional yang terdapat dalam catatan atas laporan keuangan perusahaan. Dari hal ini, terlihat fenomena belum adanya transparansi mengenai besaran audit fee di Indonesia, karena pada dasarnya di Indonesia memang belum ada ketentuan yang mengharuskan kantor akuntan publik yang mempublikasikan besarnya fee audit yang diterima sebagaimana praktek yang sudah berlangsung di negara-negara maju.

Dalam menentukan audit fee terdapat tiga dimensi yang menjadi faktor penentu, yaitu berdasarkan client attributes, auditor attributes, dan engagement attributes. Dimensi Client Attributes terdiri dari beberapa indikator, yaitu size, kompleksitas, resiko inheren, profitabilitas, leverage \& liquidty, dan industri. Sedangkan dimensi Auditor Attributes terdiri dari spesialisasi auditor, audit tenure, dan lokasi. Dan dimensi yang terakhir yaitu Engagement Attributes yang terdiri dari audit problems, audit report lag, busy season, dan number of reports. 
Berdasarkan uraian latar belakang masalah tersebut, maka yang menjadi permasalahan dalam penelitian ini adalah: (1) Bagaimana persepsi auditor mengenai urutan faktor-faktor penting dalam menentukan audit fee berdasarkan perspektif client attributes; (2) Bagaimana persepsi auditor mengenai urutan faktor-faktor penting dalam menentukan audit fee berdasarkan perspektif auditor attributes; (3) Bagaimana persepsi auditor mengenai urutan faktor-faktor penting dalam menentukan audit fee berdasarkan perspektif engagement attributes.

\section{Kajian Pustaka}

Profesi auditor dikenal masyarakat dari jasa audit yang disediakan untuk para pemakai laporan keuangan. Tumbuh dan berkembangnya profesi ini sejalan dengan berkembangnya perusahaan atau organisasi dan berbagai bentuk badan hukum manajemen serta berbagai pihak lain di luar perusahaan yang masingmasing berkepentingan dengan informasi keuangan yang disajikan, dan auditor merupakan pihak ketiga yang independen untuk menilai kehandalan laporan keuangan yang disajikan oleh pihak manajemen untuk pemakai laporan keuangan.

Seorang auditor merupakan seseorang yang memiliki predikat professional. Dan sebagai seorang yang professional, auditor harus bertingkah laku dan bersikap sesuai dengan standar auditing yang telah ditetapkan oleh Ikatan Akuntan Publik Indonesia (IAPI), karena dibutuhkannya kepercayaan publik yang tinggi atas kualitas jasa yang diberikan. Kepercayaan yang besar dari pemakai laporan keuangan auditan dan jasa lainnya yang diberikan oleh auditor inilah yang akhirnya mengharuskan auditor memperhatikan kualitas audit yang dihasilkannya. Tidak terlepas dari profesi dan tanggung jawabnya, setelah melakukan tugas dan tanggung jawabnya, auditor akan mendapatkan imbalan jasa atau fee audit yang merupakan pendapatan bagi seorang auditor. Besaran fee yang diterima oleh auditor berbeda tergantung kepada penugasan audit. Iskak dalam Michell Suharli (2008) mengatakan audit fee merupakan honorarium yang dibebankan oleh akuntan publik kepada perusahaan aduitee atas jasa audit yang dilakukan akuntan publik terhadap laporan keuangan.

Faktor penentu fee audit dapat dilihat dari 3 (tiga) ciri. David Hay (2006) mengatakan ketiga ciri penentu fee audit adalah ciri klien (client attributes), ciri auditor (auditor attributes), dan ciri penugasan (engagement attributes). David Hay (2006) menyebutkan faktor penentu dilihat dari ciri klien seperti ukuran perusahaan (size), kompleksitas operasi perusahaan (complexity), resiko inhenren atau bawaan (inherent risk), profitabilitas (profitability), likuiditas perusahaan (leverage and liquidity), dan jenis industri klien tersebut (industry). Ciri kedua yaitu ciri auditor (auditor attributes) merupakan faktor penentu besarnya audit fee yang berkenaan dengan auditor yang dilihat dari spesialisasi (specialization), waktu yang diperlukan untuk mengaudit (tenure), dan lokasi tempat mengaudit (location). Ciri penugasan (engagement attributes) merupakan faktor penentu besarnya audit fee yang berkenaan dengan penugasan audit yang dilihat dari masalah audit (audit problems), jarak waktu antara tanggal neraca dan tanggal laporan audit (lag), busy season, dan jumlah laporan yang dibuat (number of reports). 
Audit fee tidak terlepas dari persepsi seorang auditor dalam mempertimbangkan faktor-faktor yang dijadikan tolak ukur dalam penentuannya. Jalaluddin Rakhmat (2009 : 51), persepsi adalah pengalaman tentang objek, peristiwa, atau hubungan-hubungan yang diperoleh dengan menyimpulkan informasi dan menafsirkan pesan. Persepsi adalah proses yang digunakan individu mengelola dan menafsirkan kesan indera mereka dalam memberikan makna kepada lingkungan mereka. Meski demikian apa yang telah dipersepsikan seseorang dapat berbeda dari kenyataan obyektif. Tidak harus selalu berbeda, namun sering terdapat ketidaksepakatan. Misalnya, dimungkinkan bahwa semua karyawan dalam perusahaan tertentu memendang organisasi sebagai tempat yang hebat untuk bekerja, kondisi kerja yang menyenangkan, tugas pekerjaan yang menarik, upah yang baik, manajemen yang bijaksana dan bertanggung jawab, namun seperti sebagian besar dari kita tahu, sangatlah tidak bisa untuk mendapatkan kesepakatan seperti itu (Stephen P. Robbins, 2007: 170). Dengan kata lain, persepsi antar satu auditor dengan auditor lainnya dalam menetukan faktor penentu audit fee tentu berbeda-beda tergantung bagaimana ia memaknai objek yang terdapat di lingkungannya.

\section{Metode Penelitian}

Metode penelitian yang digunakan adalah metode deskriptif. Menurut Sugiono (2010:206), metode deskriptif adalah suatu metode yang digunakan untuk menganalisa data dengan cara mendeskripsikan atau menggambarkan data yang telah terkumpul sebagaimana adanya tanpa bermaksud membuat kesimpulan yang berlaku untuk umum atau generalisasi.

Dalam penelitian ini jenis data yang digunakan adalah data primer. Data primer yang dijadikan sumber data berupa kuesioner yang diberikan kepada responden. Sumber data diperoleh dengan cara menyebarkan kuesioner ke Kantor Akuntan Publik di Bandung dengan responden yaitu supervisor/partner audit.

Populasi dalam penelitian ini adalah Kantor Akuntan Publik di Bandung. Populasi yang digunakan berjumlah 28 Kantor Akuntan Publik. Teknik sampel yang digunakan adalah non probability sampling dengan pendekatan purposive sampling. Berdasarkan teknik tersebut maka diambil sebanyak 11 sampel Kantor Akuntan Publik.

Variabel dalam penelitian ini adalah audit fee digambarkan oleh tiga dimensi, yaitu client attributes, auditor attributes, dan engagement attributes. Penelitian ini menggunakan teknik statistik deskriptif. Adapun teknik statistik yang digunakan adalah Partial Least Square Confirmatory Factor Analysis.

\section{Hasil dan Pembahasan}

Client attributes dinilai merupakan dimensi yang paling dominan dalam menentukan audit fee. Dengan menggunakan loading factor Client Attributes dapat diurutkan dari faktor yang dominan sampai faktor yang tidak dominan yaitu ukuran perusahaan (0.904), kompleksitas (0.870), profitabilitas (0.825), resiko bawaan (0.822), industri (0.785), dan leverage dan liquidity (0.650). Dengan menggunakan loading factor Auditor Attributes dapat diurutkan dari faktor yang dominan sampai faktor yang tidak dominan yaitu audit tenure (0.939), lokasi 
(0.881), dan spesialisasi auditor (0.854). Dengan menggunakan loading factor Engagement Attributes dapat diurutkan dari faktor yang dominan sampai faktor yang tidak dominan yaitu audit report lag (0.871), busy season (0.806), audit problems $(0.800)$, dan number of reports $(0.559)$.

\section{Analisis Data dan Pengujian Hipotesis}

Terdapat 13 pernyataan dengan menggunakan Rank Spearman, semua pernyataan dinyatakan valid karena memiliki $r_{\text {hitung }}$ yang lebih besar dari 0,3 . Berikut hasil uji validitas yang disajikan dalam bentuk tabel :

Tabel 1

Hasil Uji Validitas Fee Audit

\begin{tabular}{|c|c|c|c|}
\hline Item Pernyataan & r tabel & r hitung & Keterangan \\
\hline 1 & 0,3 & 0,815 & Valid \\
\hline 2 & 0,3 & 0,769 & Valid \\
\hline 3 & 0,3 & 0,824 & Valid \\
\hline 4 & 0,3 & 0,802 & Valid \\
\hline 5 & 0,3 & 0,694 & Valid \\
\hline 6 & 0,3 & 0,772 & Valid \\
\hline 7 & 0,3 & 0,874 & Valid \\
\hline 8 & 0,3 & 0,862 & Valid \\
\hline 9 & 0,3 & 0,759 & Valid \\
\hline 10 & 0,3 & 0,783 & Valid \\
\hline 11 & 0,3 & 0,875 & Valid \\
\hline 12 & 0,3 & 0,715 & Valid \\
\hline 13 & 0,3 & 0,583 & Valid \\
\hline
\end{tabular}

1. Uji Reliabilitas

Uji reliabilitas dalam penelitian ini adalah dengan menggunakan metode koefisien Cronbach Alpha.

\section{Tabel 2}

\section{Hasil Uji Reliabilitas}

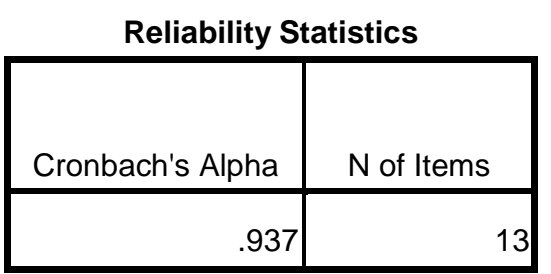

Dengan melihat tabel diatas, maka variabel fee audit diperoleh nilai Alpha Cronbach's sebesar 0,937, maka dinyatakan reliabel karena > 0,60.

\section{Loading Factor}


Dalam deskripsi variabel audit fee digunakan model pengukuran yaitu dengan menggunakan Partial Least Square (CFA). Model pengukuran merupakan model yang menghubungkan antara variabel laten dengan variabel manifes. Pada penelitian ini terdapat 1 variabel laten dengan jumlah variabel manifes sebanyak 13. Variabel audit fee dengan dimensi Client Attributes terdiri dari 6 variabel manifes, dimensi Auditor Attributes terdiri dari 3 variabel manifes, dan dimensi Engagement Attributes terdiri dari 4 variabel manifes. Menggunakan metode estimasi Partial Least Square diperoleh diagram jalur full model faktor-faktor yang dominan dalam menentukan audit fee seperti terlihat pada gambar sebagai berikut :

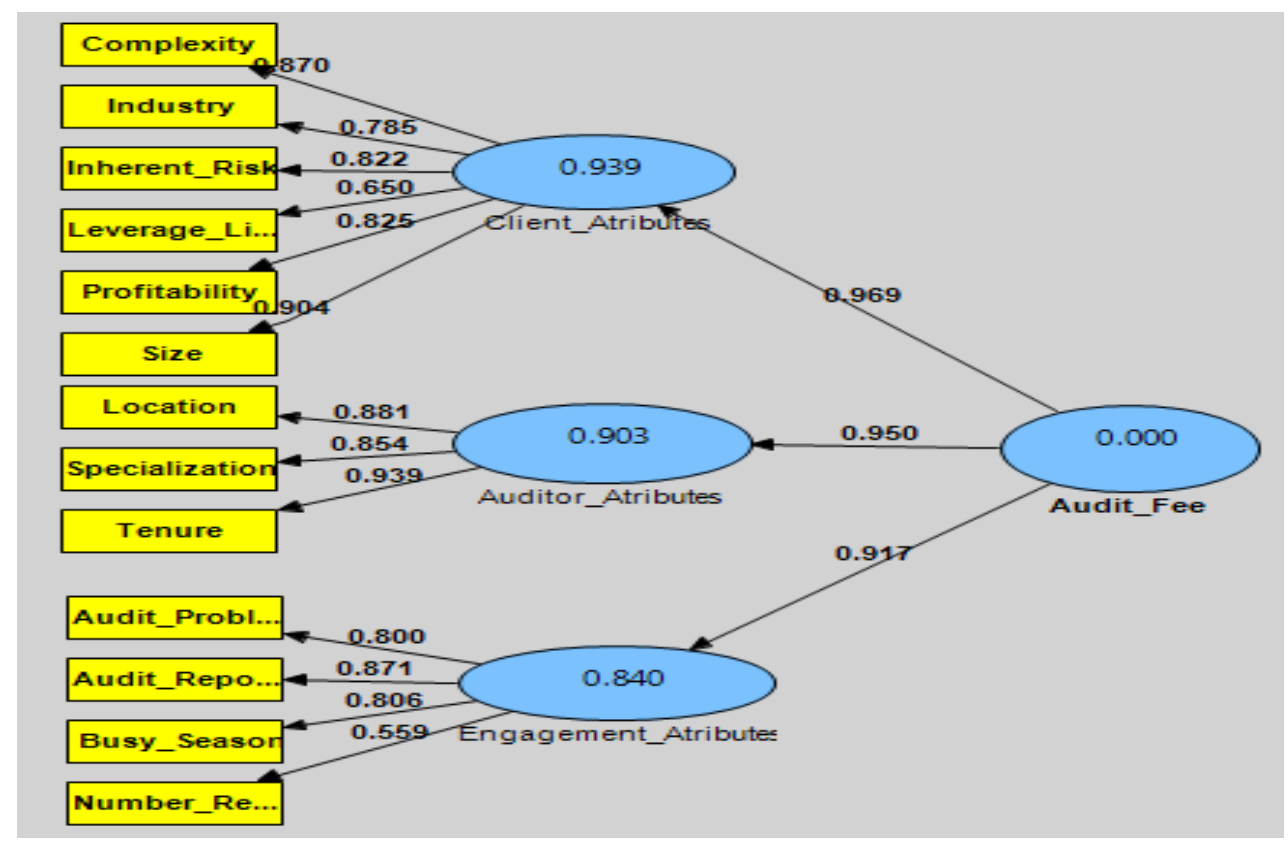

\section{Gambar 1.1}

Loading Factor Audit Fee

Berdasarkan hasil pengujian tersebut, maka : (1) Client Attributes dapat diurutkan dari faktor yang dominan sampai faktor yang tidak dominan yaitu ukuran perusahaan (0.904), kompleksitas (0.870), profitabilitas (0.825), resiko bawaan (0.822), industri (0.785), dan leverage dan liquidity (0.650); (2) Auditor Attributes dapat diurutkan dari faktor yang dominan sampai faktor yang tidak dominan yaitu audit tenure (0.939), lokasi (0.881), dan spesialisasi auditor (0.854); (3) Engagement Attributes dapat diurutkan dari faktor yang dominan sampai faktor yang tidak dominan yaitu audit report lag (0.871), busy season (0.806), audit problems (0.800), dan number of reports (0.559). 
3. Metode Bootstrapping

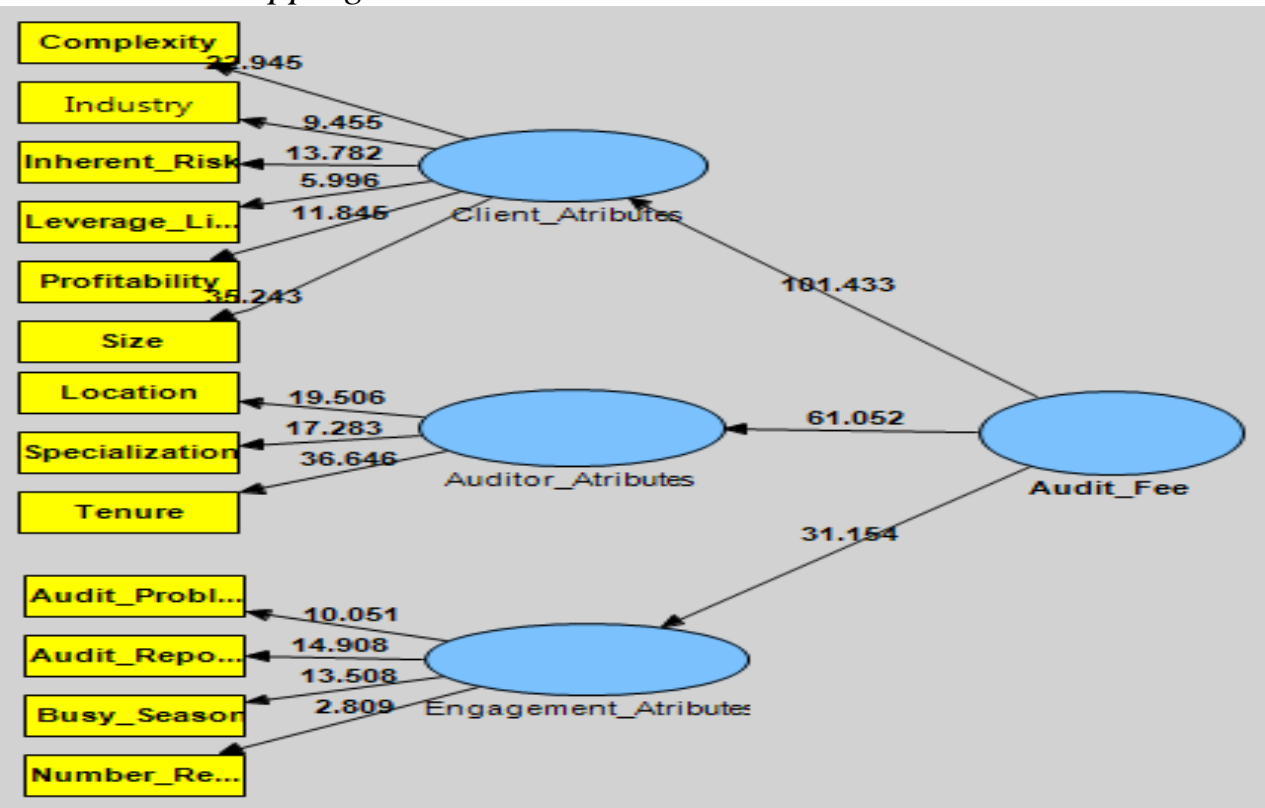

Gambar 4.2

Metode Bootstrapping Variabel Audit Fee

Melalui bobot faktor yang terdapat pada gambar 4.2 selanjutnya dapat dinilai validitas dari masing-masing indikator serta menguji reliabilitas dari konstruk variabel yang diteliti. Indikator yang memiliki loading factor kurang dari 0,50 akan didrop dari model, sedangkan composite reliability yang dianggap memuaskan adalah lebih besar dari 0,70.

\section{Tabel 3}

\section{Bobot Faktor Dimensi Client Attributes}

\begin{tabular}{|l|r|c|r|r|}
\hline \multicolumn{1}{|c|}{ Variabel manifest } & $\begin{array}{c}\text { Loading } \\
\text { Factor }\end{array}$ & Measurement model & $\mathbf{R}^{\mathbf{2}}$ & $\mathbf{t}_{\text {hitung }}$ \\
\hline $\mathrm{CA}_{1}$ (size) & 0.904 & $\mathrm{CA}=0.904 \mathrm{CA}_{1}+0.183$ & 0.817 & 35.243 \\
\hline $\mathrm{CA}_{2}$ (kompleksitas) & 0.870 & $\mathrm{CA}=0.870 \mathrm{CA}_{2}+0.243$ & 0.757 & 22.945 \\
\hline $\mathrm{CA}_{3}$ (resiko bawaan) & 0.822 & $\mathrm{CA}=0.822 \mathrm{CA}_{3}+0.324$ & 0.676 & 13.782 \\
\hline $\mathrm{CA}_{4}$ (profitabilitas) & 0.825 & $\mathrm{CA}=0.825 \mathrm{CA}_{4}+0.319$ & 0.681 & 11.845 \\
\hline $\begin{array}{l}\mathrm{CA}_{5} \\
\text { (leverage\&liquidity) }\end{array}$ & 0.650 & $\mathrm{CA}=0.650 \mathrm{CA}_{5}+0.577$ & 0.423 & 5.996 \\
\hline $\mathrm{CA}_{6}$ (industri) & 0.785 & $\mathrm{CA}=0.785 \mathrm{CA}_{6}+0.384$ & 0.616 & 9.455 \\
\hline \multicolumn{4}{|c|}{ Composite reliability $(\mathrm{CR})=0.921$} \\
\hline \multicolumn{4}{|c|}{ Average Variance Extracted $(\mathrm{AVE})=0.662$} \\
\hline
\end{tabular}

Hasil bobot faktor (nilai loading) untuk keenam variabel manifes yang diperoleh menunjukkan bahwa indikator yang digunakan untuk mengukur Audit Fee valid dan reliabel. Hal ini ditunjukkan dengan nilai loading untuk masingmasing variabel manifes lebih besar dari 0,5 dan juga dari hasil pengujian 
diperoleh nilai t hitung lebih besar dari nilai kritis 1,96 . Artinya indikator yang digunakan tersebut secara signifikan mampu merefleksikan variabel Audit Fee.

Nilai Composite Reliability untuk laten dimensi Client Attributes sebesar 0,921. Nilai yang diperoleh menunjukkan tingkat kesesuaian indikator dalam membentuk konstruk laten variabel Audit Fee sebesar 0,887 dalam skala 0-1. Nilai average variance extracted sebesar 0,662 menunjukkan bahwa $66.2 \%$ informasi yang terdapat pada variabel manifes (keenam indikator) dapat tercermin melalui dimensi Client Attributes. Diantara keenam indikator, $\mathrm{CA}_{1}$ (ukuran perusahaan) paling kuat dalam merefleksikan variabel laten Client Attributes, sebaliknya $\mathrm{CA}_{5}$ (Leverage dan Liqudity) paling lemah dalam merefleksikan variabel laten Client Attributes.

Tabel 4

Bobot Faktor Auditor Attributes

\begin{tabular}{|l|r|l|r|c|}
\hline Variabel manifest & $\begin{array}{c}\text { Loading } \\
\text { Factor }\end{array}$ & Measurement model & $\mathbf{R}^{\mathbf{2}}$ & $\mathbf{t}_{\text {hitung }}$ \\
\hline $\mathrm{AA}_{1}$ (spesialisasi) & 0.854 & $\mathrm{AA}=0.854 \mathrm{AA}_{1}+0.271$ & 0.729 & 17.283 \\
\hline $\mathrm{AA}_{2}$ (tenure) & 0.939 & $\mathrm{AA}=0.939 \mathrm{AA}_{2}+0.118$ & 0.882 & 36.646 \\
\hline $\mathrm{AA}_{3}$ (lokasi) & 0.881 & $\mathrm{AA}=0.881 \mathrm{AA}_{3}+0.224$ & 0.776 & 19.506 \\
\hline \multicolumn{4}{|c|}{ Composite reliability $(\mathrm{CR})=0.921$} \\
\hline \multicolumn{5}{|c|}{ Average Variance Extracted $(\mathrm{AVE})=0.796$} \\
\hline
\end{tabular}

Hasil bobot faktor (nilai loading) untuk ketiga variabel manifes yang diperoleh menunjukkan bahwa indikator yang digunakan untuk mengukur Audit Fee valid dan reliabel. Hal ini ditunjukkan dengan nilai loading untuk masingmasing variabel manifes lebih besar dari 0,5 dan juga dari hasil pengujian diperoleh nilai t hitung lebih besar dari nilai kritis 1,96. Artinya indikator yang digunakan tersebut secara signifikan mampu merefleksikan variabel Audit Fee.

Nilai Composite Reliability untuk laten dimensi Auditor Attributes sebesar 0,921 . Nilai yang diperoleh menunjukkan tingkat kesesuaian indikator dalam membentuk konstruk laten variabel Audit Fee sebesar 0,921 dalam skala 0-1. Nilai average variance extracted sebesar 0,796 menunjukkan bahwa 79,6\% informasi yang terdapat pada variabel manifes (ketiga indikator) dapat tercermin melalui dimensi Auditor Attributes. Diantara ketiga indikator, $\mathrm{AA}_{2}$ (audit tenure) paling kuat dalam merefleksikan variabel laten Auditor Attributes, sebaliknya $\mathrm{AA}_{1}$ (spesialisasi auditor) paling lemah dalam merefleksikan variabel laten Auditor Attributes.

Tabel 5

Bobot Faktor Engagement Attributes

\begin{tabular}{|l|c|l|c|c|}
\hline \multicolumn{1}{|c|}{ Variabel manifest } & $\begin{array}{c}\text { Loading } \\
\text { Factor }\end{array}$ & Measurement model & $\mathbf{R}^{\mathbf{2}}$ & $\mathbf{t}_{\text {hitung }}$ \\
\hline $\mathrm{EA}_{1}$ (audit problems) & 0.800 & $\mathrm{EA}=0.800 \mathrm{EA}_{1}+0.271$ & 0.640 & 10.051 \\
\hline $\mathrm{EA}_{2}$ (audit report lag) & 0.871 & $\mathrm{EA}=0.871 \mathrm{EA}_{2}+0.118$ & 0.759 & 14.908 \\
\hline $\mathrm{EA}_{3}$ (busy season) & 0.806 & $\mathrm{EA}=0.806 \mathrm{EA}_{3}+0.224$ & 0.650 & 13.508 \\
\hline $\mathrm{EA}_{4}$ (number of reports) & 0.559 & $\mathrm{EA}=0.559 \mathrm{EA}_{4}+0.224$ & 0.312 & 2.809 \\
\hline \multicolumn{5}{|c|}{ Composite reliability $(\mathrm{CR})=0.849$} \\
\hline
\end{tabular}


Average Variance Extracted (AVE) $=0.590$

Hasil bobot faktor (nilai loading) untuk ketiga variabel manifes yang diperoleh menunjukkan bahwa indikator yang digunakan untuk mengukur Audit Fee valid dan reliabel. Hal ini ditunjukkan dengan nilai loading untuk masingmasing variabel manifes lebih besar dari 0,5 dan juga dari hasil pengujian diperoleh nilai t hitung lebih besar dari nilai kritis 1,96. Artinya indikator yang digunakan tersebut secara signifikan mampu merefleksikan variabel Audit Fee.

Nilai Composite Reliability untuk laten dimensi Enaggement Attributes sebesar 0,849 . Nilai yang diperoleh menunjukkan tingkat kesesuaian indikator dalam membentuk konstruk laten variabel Audit Fee sebesar 0,849 dalam skala 01. Nilai average variance extracted sebesar 0,590 menunjukkan bahwa 59\% informasi yang terdapat pada variabel manifes (keempat indikator) dapat tercermin melalui dimensi Engagement Attributes. Diantara keempat indikator, $\mathrm{EA}_{2}$ (audit report lag) paling kuat dalam merefleksikan variabel laten Engagement Attributes, sebaliknya $\mathrm{EA}_{4}$ (number of reports) paling lemah dalam merefleksikan variabel laten Engagement Attributes.

\section{Simpulan}

Berdasarkan hasil penelitian dan pembahasan mengenai faktor penentu audit fee pada Kantor Akuntan Publik d Bandung, maka dapat ditarik kesimpulan sebagai berikut :

1. Client attributes merupakan dimensi yang dominan dalam menentukan audit fee. Client attributes yang terdiri dari enam indikator dapat diurutkan dari hasil yang dominan sampai yang tidak dominan sebagai faktor penentu audit fee adalah size, kompleksitas, profitabilitas, resiko bawaan, industri, dan leverage liqudity.

2. Auditor attributes yang terdiri dari tiga indikator dapat diurutkan dari hasil yang sangat penting sampai yang tidak begitu penting sebagai faktor penentu audit fee adalah yaitu audit tenure, lokasi, dan spesialisasi auditor.

3. Engagement attributes yang terdiri dari empat indikator dapat diurutkan dari hasil yang sangat penting sampai tidak begitu penting sebagai faktor penentu audit fee adalah audit report lag, musim sibuk, permasalahan audit (audit problems), dan jumlah laporan.

\section{Saran}

Berdasarkan pembahasan dan pengambilan kesimpulan yang telah dilakukan terhadap hasil penelitian, maka penulis mengajukan saran sebagai berikut:

1. Kantor Akuntan Publik dalam menetapkan fee audit harus tetap berpedoman pada ketentuan yang telah diatur oleh IAPI.

2. Perusahaan perlu mempublikasikan tarif fee audit kedalam laporan keuangan sebagai salah satu bentuk transparansi.

3. Bagi penelitian selanjutnya, sebaiknya memperluas lingkup penelitian dengan memperbanyak jumlah sampel yang akan diteliti, menambah faktor-faktor lain yang dapat dijadikan sebagai faktor penentu fee audit di Indonesia, mengambil objek penelitian selain kota Bandung atau Indonesia, responden 
lebih beragam dan karakteristik responden lebih dikhususkan agar tujuan dari penelitian dapat tercapai secara optimal.

\section{Daftar Pustaka}

Agoes, Sukrisno. (2004). Auditing (Pemeriksaan Akuntan) oleh Kantor Akuntan Publik. Edisi Ketiga. Penerbit Fakultas Ekonomi Universitas Trisakti.

Al Shammari, et al. (2008). "Determinants of Audit Fees in Kuwait". Journal Academy Business Economics. Vol 8.

Arens, Alvin A, and James K. Loebbecke. (2008). Auditing dan Jasa Assurance Edisi 12 Jilid I. Jakarta : Erlangga.

Arens, Alvin A, and James K. Loebbecke. (2008). Auditing dan Jasa Assurance Edisi 12 Jilid 2. Jakarta : Erlangga.

Arens, Alvin \& James. (2006) .Auditing Edisi Indonesia, Alih bahasa oleh Amir. Abadi Yusuf. Jakarta: Salemba Empat.

Atkinson, Rita L. (2002). Pengantar Psikologi Edisi 11 Jilid I. Batam : Interaksa.

B. Santoso, Purbayu \& Azhari. (2005). Analisis Statistik Dengan Ms. Excel \& SPSS. Yogyakarta : Andi.

Basioudis, et al. (2004). "The Market For Professional Services in Indonesia". International Journal of Auditing. Vol 8. p. 153-164.

Bursa Efek Indonesia. (2011). Laporan Keuangan Perusahaan. Jakarta : Bursa Efek Indonesia.

Cameran. (2005). "Audit Fess and the Large Auditor Premium in the Italian Market". International Journal of Auditing. Vol.9.p. 129-146.

David Hay. (2006). "The Accumulated Weight of Evidence in Audit Fee Research". sumber internet.

Ghozali, Imam. (2011). Structural Quation Model Metode Alternatif Dengan Partial Least Square (PLS) Edisi 3. Semarang : Badan penerbit Universitas Diponegoro.

Holmes, Arthur W.,and Burns, David C. (1979). Auditing Norma dan Prosedur. Jakarta : Erlangga.

Husein, Umar. (2003). Metode Riset Akuntansi Terapan. Jakarta : Ghalian Indonesia.

Indriantoro, Nur dan Bambang Supomo. (2002). Metodologi Penelitian Bisnis Untuk Akuntandi dan Manajemen. Yogyakarta : BPFE.

Rahayu, Siti Kurnia dan Ely Suhayati. (2009). Auditing Konsep Dasar dan Pedoman Pemeriksaan Akuntan Publik. Bandung : Graha Ilmu.

Rakhmat, Jalaluddin. (2009). Psikologi Komunikasi. Bandung : PT. Remaja Rosdakarya.

Riduwan. (2007). Metode \& Teknik Menyusun Tesis. Bandung : CV. Alfabeta.

Rivai, Veithzal dan Deddy Mulyadi. (2009). Kepemimpinan dan Perilaku Organisasi. Jakarta : Rajawali Pers.

Robbins, Stephen P.(2007). Perilaku Organisasi Edisi Sepuluh. Prentice Hall.

Robbins, Stephen P.(2011). Perilaku Organisasi Buku 2 Edisi Kedua Belas. Jakarta : Salemba Empat. 
Sawir, Agnes. (2008). Kebijakan Pendanaan dan Restrukturisasi Perusahaan. Jakarta : PT. Gramedia Pustaka Utama.

Sofia, Khalida. 2011. Pengaruh Human Capital Terhadap Kinerja Auditor. Publikasi Jurusan Pendidikan Akuntansi FPEB UPI: Bandung: tidak diterbitkan.

Sudjana. (2004). Statistika Edisi Kelima Jilid I. Bandung : Tarsito.

Sugiyono. (2012). Metode Penelitian Bisnis. Bandung : Alfabeta.

Suharli, Michell, et al. (2008). "Konsentrasi Auditor dan Penetapan Fee Audit : Investigasi Pada BUMN”. JAAI. Vol. 12 No. 2. p. 132-150.

Thoha, Miftah. (1998). Perilaku Organisasi. Jakarta : PT. Raja Grafindo Persada.

Tuanakotta, Theodorus M. (2011). Berpikir Kritis dalam Auditing. Jakarta : Salemba Empat.

Ulum, Ihyaul. (2009). Audit Sektor Publik Suatu Pengantar. Jakarta : Bumi Aksara.

Walgito, Bimo. (2002). Psikologi Sosial. Yogya : Andioffset.

P.L Joshi and Hasan Al-Bastaki. (2000). "Determinants of Audit Fees : Evidence From the Companies Listed in Bahrain". International Journal of Auditing. Vol 4.p. 129-138.

Ming - Wei Zhang and Steven Myrteza. (1996). "The Determinants of Audit Fees : Australian Perspective". Asian Review Accounting. Vol 4.p. 81-97.

www.proper.mnlh.go.id . Daftar Nama perusahaan Manufaktur di Bandung 